\title{
Three-dimensional Visualization of Particulate Matter Data Focused on Metropolitan and Gangnam Station Areas in South Korea
}

\author{
Se Hun Oh, ${ }^{1}$ Seon Cheol Yu, ${ }^{2}$ and Jong Wook Ahn ${ }^{3 *}$ \\ ${ }^{1}$ Corporate Business Support Group, AllForLand, \\ 1401-ho, 145, Gasan digital 1-ro, Geumcheon-gu, Seoul 08506, Korea \\ ${ }^{2}$ Dept. of Smart City Engineering, Anyang University, \\ 22, Smadeok-ro 37beon-gil, Manan-gu, Anayang-si, Gyeonggi-do 14028, Korea \\ ${ }^{3}$ Dept. of Smart City Engineering, Anyang University, \\ 22, Smadeok-ro 37beon-gil, Manan-gu, Anayang-si, Gyeonggi-do 14028, Korea
}

(Received May 25, 2021; accepted August 3, 2021)

Keywords: three-dimensional frame, visualization, particulate matter data, Korea

In this paper, we propose a method of effectively visualizing particulate matter data based on a 3D spatial grid system to overcome the limitations of 2D spatial information. The metropolitan area in Korea was set as the demonstration site for the regional scope, whereas the Gangnam Station area in Seoul, South Korea, was set for the local scope. The particulate matter data were collected from the Korean Air Quality Forecasting System (KAQFS), public data, and private corporations. The 3D data were created by applying the GRS80 coordinate transformation and GIS spatial interpolation according to the data attribute. Moreover, the grid size was determined according to the spatial scope, and the data were structuralized for a library application. For the empirical analysis, the 3D particulate matter data were visualized by building an open-sourcebased 3D Geospatial Grid Library. The results demonstrated that the 3D spatial distribution of particulate matter data for each time series can be visualized, which can be used as scientific evidence for establishing policies related to particulate matter.

\section{Introduction}

The urbanization process in most countries around the world has accelerated resulting from the increase in the influx of people to cities. Therefore, the horizontal structure of cities has gradually become vertical owing to the limited space, advances in construction technology, and the efficient utilization of national land. Efforts have recently been made to create 3D spatial information because of the increasing importance of obtaining height information according to the changes in the physical environment. Three-dimensional spatial information overcomes the limitation of the abstractness of 2D spatial information and provides necessary information for real-world applications. Furthermore, the demand for such information has exponentially increased in the era of the Fourth Industrial Revolution. In particular, the possibility of using 3D

*Corresponding author: e-mail: ajw0603@anyang.ac.kr

https://doi.org/10.18494/SAM3440 
information as an integrated platform is being discussed along with the development of smart cities. In Korea, because of the increase in the demand for 3D spatial information, central and local government bodies, including the Ministry of Land, Infrastructure and Transport and Seoul City, as well as private enterprises such as Daum Kakao, are now committed to providing services related to building a 3D information system. In other countries such as Singapore and the United States, various systems, including the Virtual City System and Google Earth, are under development to accommodate the increasing demand for 3D spatial information. Mapbased 3D spatial information enables intuitive understanding of a space through immersive virtual experience and 3D visualization. ${ }^{(1,2)}$ In addition, 3D spatial information can achieve better and more comprehensive decision-making support in geospatial related projects. ${ }^{(3)}$ The visualization of 3D spatial information refers to representing the information as similarly as possible to the real world by adding height (depth) and attributes to 2D spatial information.

Recently, the importance and attention on environment protection in East Asia have increased. In particular, international collaborative research is being conducted among Korea, Japan, and China to effectively respond to the issue of particulate matter. Particulate matter is classified as a Group 1 carcinogen by the International Agency for Research on Cancer, which is part of the World Health Organization. ${ }^{(4)}$ Particulate matter floats in air and quickly dissipates in a manner depending on the weather and atmospheric factors, leading to difficulties in delivering information of dynamic particulate matter in the atmosphere. ${ }^{(5,6)}$ Moreover, a difficulty is encountered in delivering information through the visualization of a de-identified (aerial) space from the perspectives of 2D and 3D spatial information.

In the present study, therefore, a method of visualizing particulate matter data (which change over time) using 3D spatial grid technology is proposed. The demonstration site was divided into regional and local scopes. The metropolitan area in Korea was selected for the regional scope, whereas the Gangnam Station area in Seoul was designated as the local scope. The data were collected from the Korean Air Quality Forecasting System (KAQFS), public data, and public and private particulate matter monitoring networks. The 3D data were constructed by coordinate transformation and spatial interpolation. Subsequently, the 3D visualization of particulate matter was performed using the 3D Geospatial Grid Library, which was developed on the basis of Web open-source data. Furthermore, research was conducted to enable intuitive information delivery in a digital space that is similar to the real world by linking it with a spatial information open platform in Korea (hereinafter referred to as V-World), which is a 3D city model.

\section{Literature Review and Framework of Analysis}

\subsection{Literature review}

In the present study, previous studies on 3D spatial grids and on the spatial analysis of particulate matter were separately investigated, and the following results were derived. Firstly, on the basis of studies about 3D spatial grids in Korea, Choi et al. (2016) ${ }^{(7)}$ introduced the concept of a spatial grid for effectively managing indoor-plant facilities. They proposed an effective spatial analysis method for indoor-plant facilities by creating 3D point-cloud 
information using laser scanning and defining an optimal 3D spatial grid size. Youn et al. $(2016)^{(8)}$ conducted research on the visualization of volcanic ash diffusion during a volcanic eruption using a 3D spatial grid. Diverse visualization methods were proposed for different purposes in an aerial spatial grid, and the aerial space was visualized using noncontinuous unit spatial grids or cubes. In other countries, Zhang et al. (2019) ${ }^{(9)}$ proposed a method of effectively forecasting convective rainstorms as a function of the altitude using a continuous 3D grid network and deep-learning technology. Wang et al. $(2017)^{(10)}$ proposed an effective Web-based analysis method for information visualization using a 3D spatial grid in the Earth science field. They distinguished grids from the highest level to the lowest level according to the level of detail using an octree-based partitioning method.

As a study conducted on the spatial analysis of particulate matter in Korea, Lee and Lee $(2015)^{(11)}$ compared the concentration in indoor and outdoor spaces using the particulate matter data collected using a simple indoor gauge and the particulate matter measurement data of a national air-pollution monitoring network. The 3D data were represented in a time series. Kim et al. (2019) ${ }^{(12)}$ performed a 3D visualization analysis of the Community Multiscale Air Quality (CMAQ) modeling results of the United States Environmental Protection Agency (US EPA) using Unreal Engine 4, which is a commercial visualization engine, and a digital elevation model (DEM). Accordingly, the feasibility of analyzing air pollution data, including particulate matter, through 3D visualization was proposed. However, the visualization of small-scale regions was limited because the study was conducted on national land. In other countries, Okuda and Kusaka (2012) ${ }^{(13)}$ performed a 3D simulation of particulate matter that blows from the deserts in China using particulate matter and wind data measured at various locations in Japan. The 3DS Max Software and Keyhole Markup Language script-based cloud animation technology were used for the 3D visualization, and statistically significant results were obtained by comparing them with secondary particulate matter concentrations. However, the study encountered a limitation in obtaining particulate matter data at the city level because it was conducted at a local scope. Isikdag and Sahin (2018) ${ }^{(14)}$ visualized particulate matter data collected from the National Air Quality (AQ) Monitoring Network of Turkey from 2008 to 2017 using 3D grids in a time series and structural shapes on the Web. A vast amount of data was effectively managed on the Web using GeoJSON and Cesium CZML file formats and the PostGIS Database. However, a limitation was experienced in expressing the data in 2.5D through a simple time series and a structural shape by generalizing a wide space into cubes.

In the present study, we propose a method of 3D visualization of particulate matter data in the aerial space using a 3D spatial grid system as a uniform partitioning method. This work is different from other previous studies in that, in this work, a visualization method for providing information on particulate matter to users and effectively providing a response by linking it to a 3D city model that resembles the real world is proposed (Table 1).

\subsection{Framework of analysis}

The framework of analysis in the current study for the 3D visualization of particulate matter data at the regional and local scopes was established as follows (Fig. 1). First, the particulate 
Table 1

Literature review and novelty of our study.

\begin{tabular}{|c|c|c|c|}
\hline Study by & & Major Content & Limitations \\
\hline \multirow{4}{*}{$\begin{array}{l}\text { Related to } \\
\text { 3D spatial } \\
\text { grids }\end{array}$} & $\begin{array}{l}\text { Choi et al. } \\
\text { (2016) }\end{array}$ & $\begin{array}{l}\text { Defined 3D spatial grid size }(0.2-0.3 \mathrm{~m}) \\
\text { of obtained point-cloud data of indoor- } \\
\text { plant facilities for efficient management and } \\
\text { spatial analysis }\end{array}$ & $\begin{array}{l}\text { Limited to conducting experiments at small } \\
\text { scale only for indoor facilities, although } \\
\text { optimal space partitioning and management } \\
\text { method proposed for indoor-plant facilities } \\
\text { using 3D spatial grid }\end{array}$ \\
\hline & $\begin{array}{l}\text { Youn et al. } \\
\text { (2016) }\end{array}$ & $\begin{array}{l}\text { Visualized volcanic ash diffusion using } \\
\text { 3D simple grid (cube) for various types of } \\
\text { data (longitude, latitude, altitude, time, and } \\
\text { concentration of volcanic ash) }\end{array}$ & $\begin{array}{l}\text { Limitation of constant separation } \\
\text { distance between grids because of use of } \\
\text { noncontinuous 3D simple grids in aerial } \\
\text { space }\end{array}$ \\
\hline & $\begin{array}{l}\text { Zhang et al. } \\
\text { (2019) }\end{array}$ & $\begin{array}{l}\text { Proposed method for forecasting convective } \\
\text { rainstorms based on radar observation in } \\
\text { China and spatial analysis of real-time } \\
\text { meteorological data by defining 3D spatial } \\
\text { grid size }\left(18 \times 18 \times 20 \mathrm{~km}^{3}\right)\end{array}$ & $\begin{array}{l}\text { Constrained to using specific grid size } \\
\text { because of limited data collected from } \\
\text { radar, although meteorological data could be } \\
\text { analyzed according to height by partitioning } \\
\text { aerial space }\end{array}$ \\
\hline & $\begin{array}{l}\text { Wang et al. } \\
\text { (2017) }\end{array}$ & $\begin{array}{l}\text { Proposed method for analyzing Earth } \\
\text { science data in Web based on efficient data } \\
\text { management and intuitive visualization } \\
\text { using 3D spatial grid }\end{array}$ & $\begin{array}{l}\text { Visualized Earth science data only within } \\
\text { local scope of virtual Earth using large grid } \\
\text { size and limited to representing local scope } \\
\text { at city level }\end{array}$ \\
\hline \multirow{4}{*}{$\begin{array}{l}\text { Related } \\
\text { to spatial } \\
\text { analysis of } \\
\text { particulate } \\
\text { matter }\end{array}$} & $\begin{array}{l}\text { Lee and Lee } \\
\text { (2015) }\end{array}$ & $\begin{array}{l}\text { Proposed method of visualizing indoor } \\
\text { spaces using floor plans or structural models } \\
\text { based on comparison of collected indoor and } \\
\text { outdoor particulate matter data }\end{array}$ & $\begin{array}{l}\text { Concentration of particulate matter } \\
\text { could be intuitively understood through } \\
\text { representation of indoor space, but } \\
\text { representation limited because of } \\
\text { generalization of space unit on floor plans }\end{array}$ \\
\hline & $\begin{array}{l}\text { Kim et al. } \\
(2019)\end{array}$ & $\begin{array}{l}\text { Performed 3D visualization of air-pollution } \\
\text { data (particulate matter) using CMAQ } \\
\text { modeling of US EPA based on DEM }\end{array}$ & $\begin{array}{l}\text { Analyzed within local scope through data } \\
\text { visualization of Korean Peninsula but } \\
\text { limited to visualization of specific region in } \\
\text { Korean Peninsula }\end{array}$ \\
\hline & $\begin{array}{l}\text { Okuda and } \\
\text { Kusaka } \\
\text { (2012) }\end{array}$ & $\begin{array}{l}\text { Proposed method for examining flow } \\
\text { of particulate matter over time for each } \\
\text { continent at altitude of } 6300 \mathrm{~m} \text { through 3D } \\
\text { cloud visualization and simulation using } \\
\text { Google Earth }\end{array}$ & $\begin{array}{l}\text { Intuitive visualization through simulation } \\
\text { of particulate matter movement for each } \\
\text { continent using Google Earth, but data } \\
\text { representation limited to local scope at city } \\
\text { level }\end{array}$ \\
\hline & $\begin{array}{l}\text { Isikdag and } \\
\text { Sahin (2018) }\end{array}$ & $\begin{array}{l}\text { Suggested method of visualizing particulate } \\
\text { matter data collected per time frame from } \\
\text { AQ Monitoring Network of Turkey using 3D } \\
\text { simple grid (cube) and changes in external } \\
\text { circumstances of buildings in Web }\end{array}$ & $\begin{array}{l}\text { Method suggested for analysis at local scope } \\
\text { through visualization of particulate matter } \\
\text { data at city level, but representation limited } \\
\text { because of use of simple vertical grids } \\
\text { and changes in external circumstances of } \\
\text { buildings instead of uniform partitioning } \\
\text { system of aerial space }\end{array}$ \\
\hline Our study & & \multicolumn{2}{|c|}{$\begin{array}{l}\text { Propose visualization method for intuitive information delivery by linking it with 3D } \\
\text { city model in Korea (V-World) and 3D representation of particulate matter data using 3D } \\
\text { Geospatial Grid Library built with Web open source }\end{array}$} \\
\hline
\end{tabular}

matter data in the metropolitan area in the regional scope were collected from the KAQFS in a NetCDF file format ${ }^{[1]}$, which is commonly used in the atmospheric environment field. The data on the Gangnam Station area in the local scope were collected from the Korea Environment Corporation and private telecommunication companies in an Excel file format. The 3D particulate matter data were included in the attributes of the metropolitan area data, and coordinate transformation to the GRS80 system was performed for application to the 3D 


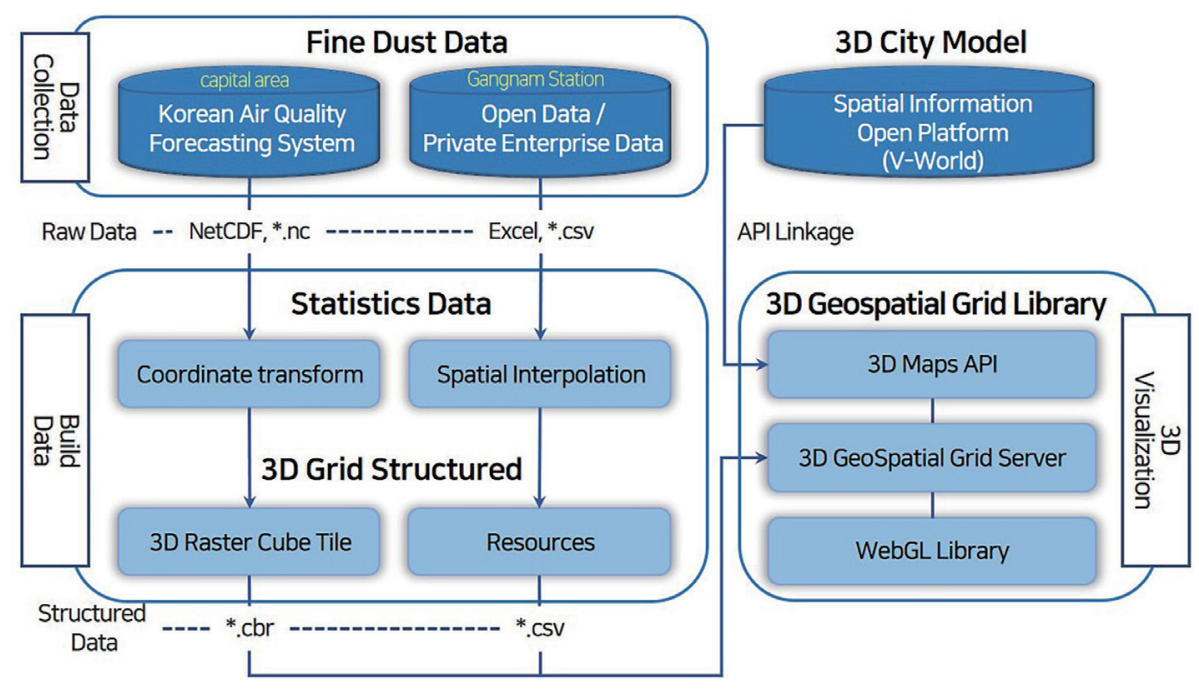

Fig. 1. (Color online) Framework of analysis.

Geospatial Grid Library. The data on the Gangnam Station area were point data that only contained the location and concentration of particulate matter. Therefore, spatial interpolation was applied to create the 3D data. The particulate matter data of the metropolitan area were converted to a unique structured data format of a 3D spatial grid, namely, *..cbr ${ }^{[2]}$, according to the defined grid form and size. Similarly, the particulate matter data on the Gangnam Station area were converted according to the defined grid form and size to include the ID of each grid point. However, the file format was maintained as *.csv in accordance with the real-time streaming structure for use in different databases in the future. Subsequently, the grid data were processed through the 3D Geospatial Grid Server. The 3D visualization was processed in a grid form through the WebGL Library based on 3D maps linked to V-World within the 3D Geospatial Grid Library.

${ }^{[1]}$ NetCDF (Network Common Data Format, *.nc) file format supports the generation, access, and sharing of sequence-oriented scientific data. It is often used in the atmospheric environment field owing to its usefulness for storing, distributing, and processing large-scale weather data and can be visualized using 3D graphics technology.

${ }^{[2]}$ CBR file format is an independent data format applicable to the 3D GeoSpatial Grid Library and is classified into raster, vector, or spatial according to the type. The file extension is always *.cbr regardless of the data form.

\section{Analysis Method and Data Construction}

\subsection{Analysis methodology}

A 3D spatial grid system is a multidimensional spatial information system that can realistically represent the real world in which de-identified spaces (underground, underwater, and aerial spaces) that cannot be recognized in 2D spatial information can be recognized. A 3D spatial grid system is a new type of positioning system that can promptly store, manage, control, and utilize (visualize) the information in the spaces that we occupy according to different purposes. ${ }^{(15-17)} \mathrm{A}$ uniform space partitioning method is applied within the defined height (depth) range (Fig. 2). 


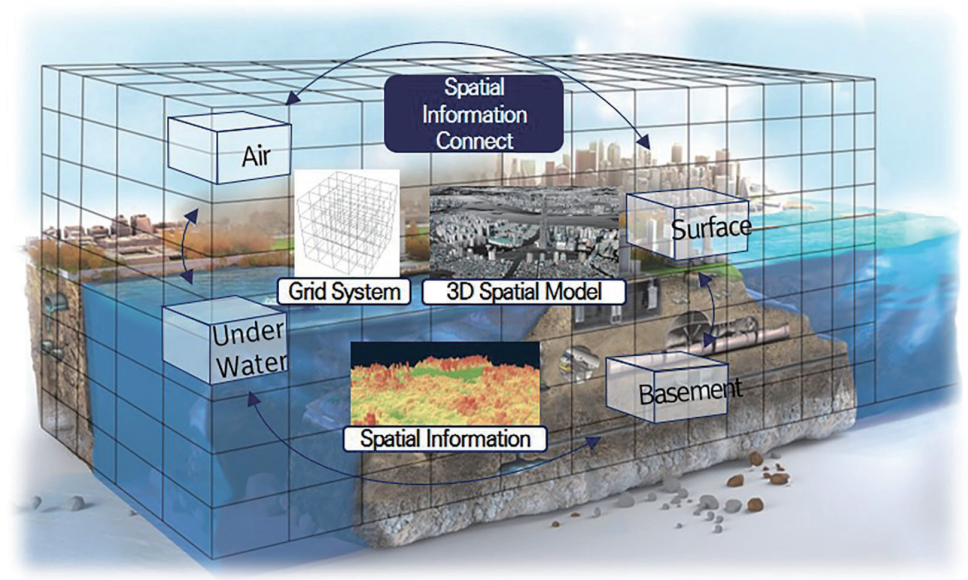

Fig. 2. (Color online) Concept of a 3D spatial grid system. Taken from Ref. 15.

The 3D spatial grids were partitioned with respect to the longitude and latitude coordinate system. In regard to the space partitioning, the number of partitions was determined as $2^{n}$ depending on the dimension, in which the partition size was identical from higher to lower levels. The highest level is typically set to $36^{\circ}$, which corresponds to that when the Earth is divided into 10 , whereas the size of the lower levels is determined using a simple equation. The grid size for the highest level was set as listed in Table 2 based on V-World built by the Korean government. The method of assigning IDs to the partitioned grids is shown in Fig. 3. The row and column at the bottom left corner are set as $(0,0)$. The depth of $10 \mathrm{~km}$ underground was set to zero for the height to prevent a negative number from being assigned as an ID. The allocation of the IDs was managed consistently by adding the number of IDs being assigned.

To apply this concept, the developed 3D spatial grid library used the GRS80 coordinate system. To combine the coordinate system of the collected data with the global coordinate system, the Poj 4 library source EPSG:4019, EPSG:4737 (Korean 2000) + proj $=$ longlat + ellps $=$ GRS80 + no_defs was used to transform the coordinates into the GRS80 coordinate system of longitude and latitude (based on seven variables in the Bursa-Wolf model of the National Coordinate Conversion Factor announced by the National Geographic Information Institute in December 2002).

Moreover, it was necessary to construct 3D data in which the height value $(z)$ is applied to the existing 2D $(x, y)$ data for 3D visualization. The collected data were point data that contained the position values of a $2 \mathrm{D}$ map unless they were $3 \mathrm{D}$ data specifically constructed by atmospheric environment modeling. Therefore, the spatial interpolation method of GIS was applied to the point data to derive the empty space and height values between the measurement station points. No study that specifically proposes the optimal spatial interpolation method to be applied in the atmospheric environment field has been conducted. However, one of the widely used techniques is Kriging spatial interpolation. ${ }^{(18,19)}$ The Kriging technique, in which the empty spaces between the measurement stations are used as weights in the spatial autocorrelation of the semi-variogram based on the collected data, was employed in this study, where the semi-variogram $\gamma$ is expressed as 
Table 2

Grid size definition in the partitioning method.

\begin{tabular}{lcc}
\hline Level & Angle & Distance of longitude (m) \\
\hline Latitude & 36.000000 & 3242136.95 \\
Level 0 & 18.000000 & 1621068.48 \\
Level 1 & 9.000000 & 810534.24 \\
Level 2 & 4.500000 & 405267.12 \\
Level 3 & 2.250000 & 202633.56 \\
$\vdots$ & $\vdots$ & $\vdots$ \\
Level 9 & 0.0703125 & 6332.30 \\
$\vdots$ & $\vdots$ & $\vdots$ \\
Level 17 & 0.00027466 & 24.74 \\
$\vdots$ & $\vdots$ & $\vdots$ \\
Level 20 & 0.00003433 & 3.09 \\
\hline
\end{tabular}

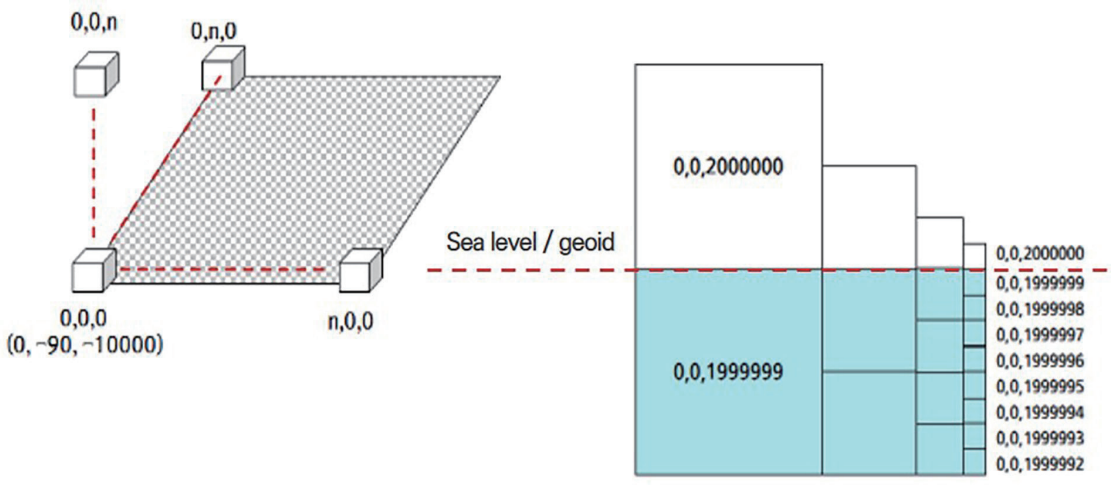

Fig. 3. (Color online) Grid ID assignment method. Taken from Ref. 15.

$$
\gamma(h)=\frac{1}{2} \frac{\sum\left[Z\left(X_{i}-Z\left(X_{i}+h\right)\right)\right]^{2}}{N}, Z(x)=\sum_{i=1}^{n} w_{i} \cdot Z_{x_{i}} .
$$

Here, $Z\left(X_{i}\right)$ are the observed values at $X_{i}, Z\left(X_{i}+h\right)$ are the observed values at a point $\mathrm{h}$ away from $X_{i}, N$ is the number of pairs of observed values divided by the distance $h, w_{i}$ is the weight due to the semi-variogram, $Z_{x_{i}}$ is the observed value at a nearby point after the calculation, and $Z(x)$ is the estimated value at the unobserved points.

The particulate matter data created by applying Kriging spatial interpolation were used to construct the 3D particulate matter data, in which the height value was set by linear spatial interpolation. As the coefficient used to apply the linear spatial interpolation, the minimum measured value of $16 \mu \mathrm{g} / \mathrm{m}^{3}$ and the maximum measured value of $25 \mu \mathrm{g} / \mathrm{m}^{3}$ used in Ref. 16 were applied. The equation for the linear spatial interpolation is 


$$
x_{2}: x_{1}=y_{2}: y_{1}, g(x)=\frac{y_{2}-y_{1}}{x_{2}-x_{1}}\left(x-x_{1}\right)+y_{1} .
$$

Here, $x_{2}$ is the minimum measured value, $x_{1}$ is the maximum measured value, $y_{2}$ is the minimum interpolated value, $y_{1}$ is the maximum interpolated value, and $g(x)$ is the estimated height value.

The particulate matter data acquired using the coordinate transformation to GRS80 and 3D conversion were constructed as structured files according to the grid level appropriate for each spatial scope of the 3D visualization using the 3D Geospatial Grid Library.

\subsection{Data construction}

A summary of the particulate matter data collected from the metropolitan and Gangnam Station areas is given in Table 3. The particulate matter data in the metropolitan area were collected from the KAQFS on the available dates. The collected data in the Lambert conformal conic (LCC) coordinate system were converted to the GRS80 coordinate system. According to the spatial scope of the metropolitan area, the grid size was set to Level 9 (approximately $6 \mathrm{~km} \times$ $6 \mathrm{~km} \times 6 \mathrm{~km})$. Then, the data were converted to structured data (*.cbr) in which a 3D raster cube tile was applied to generate the grids.

The data in the Gangnam Station area were collected from the Korea Environment Corporation and private telecommunication companies from 37 locations around Gangnam Station on March 5, 2019, when the concentration of particulate matter was particularly high. Coordinate transformation was not performed because the data were already in the GRS 80 coordinate system. However, the collected data were 2D point data, which did not contain height values. Thus, spatial interpolation was applied to create the 3D data. Then, the grid size was set to Level 17 (approximately $25 \mathrm{~m} \times 25 \mathrm{~m} \times 25 \mathrm{~m}$ ) according to the scope of the visualization site. Subsequently, the data were converted to structured data (*.csv) using the 3D Geospatial Grid Library to contain the unique ID and concentration value of each grid.

Table 3

Particulate matter data.

\begin{tabular}{|c|c|c|c|}
\hline \multicolumn{2}{|l|}{ Category } & Metropolitan area & Gangnam Station \\
\hline \multicolumn{2}{|l|}{ Source } & Korean Air Quality Forecasting System & Public data/private corporation data \\
\hline \multicolumn{2}{|l|}{ Date/time } & 2019.11.28 9:00 - 2019.12.04 00:00 (132 h) & $2019.03 .05(24 \mathrm{~h})$ \\
\hline \multicolumn{2}{|c|}{ Data volume } & $3.2 \mathrm{~GB}$ & $2 \mathrm{MB}$ \\
\hline \multicolumn{2}{|c|}{ Data format } & $\operatorname{NetCDF}(* . n c)$ & Excel $(* . c s v)$ \\
\hline \multirow{4}{*}{$\begin{array}{l}\text { Attribute } \\
\text { data }\end{array}$} & $\begin{array}{l}\text { Coordinate } \\
\text { system }\end{array}$ & LCC & GRS80 \\
\hline & Coordinates & $x, y, z$ & $x, y+$ address \\
\hline & $\begin{array}{l}\text { Base } \\
\text { coordinates }\end{array}$ & $x, y, z$ & - \\
\hline & $\begin{array}{l}\text { Concentration } \\
\text { of particulate } \\
\text { matter }\end{array}$ & $\mathrm{Pm}_{10}$ & $\mathrm{Pm}_{10}$ \\
\hline
\end{tabular}




\section{Results of Visualization Analysis}

\subsection{Analysis environment}

The 3D Geospatial Grid Library, which was developed for the 3D visualization of particulate matter data, was constructed by combining the functions of open sources available on the Web. For the basic software development environment, a Java language-based standard framework for e-government (eGovFrame) and Servlet and JSP were used. Fundamentally, a 3D environment should be built for the visualization of the grid data. In this study, the system was expanded on the basis of 3D for Web Client, ${ }^{[3]}$ which was provided as an open source to implement the functions. Furthermore, an environment that resembles the real world was created in the digital space using V-World, which is a 3D city model, and an API linkage. The S/W development environment is classified into 3D for Web Client, 3D GeoSpatial Grid Server, 3D GeoSpatial Grid Web Browser, and V-World. The S/W development environment is shown in Fig. 4.

The 3D geospatial grid server was built on the basis of 3D for Web Client. In the server, GIS and 3D geospatial grid data were stored, managed, and processed using PostGIS and 3D Tiles. According to this configuration, the dynamic and static data were processed using the Web/ WAS server built using Apache/Tomcat to secure interoperability between the server and the browser. The data were processed in a background thread, which was separate from the user interface, by applying WebWorker technology, thus enabling the parallel processing of the data.

The 3D geospatial grid Web browser was built using HTML5, CSS3, and JavaScript Language. Therefore, visualization could be performed in all browsers that support HTML5 (IE11+, Edge, Chrome, Safari, and Opera), and the expansion was rather simple, using an opensource-based S/W development. The 3D GIS and 3D geospatial grids that responded to the server were visualized in three dimensions using the open-source-based WebGL Library. The 3D data could be quickly visualized using standard Web technology without a separate ActiveX or plug-in. The specifications of the computer hardware used for the 3D visualization of the particulate matter data using the 3D Geospatial Grid Library are listed in Table 4.

${ }^{[3]}$ demo.cmworld.net:18080/cmworld_maps_api/about3d

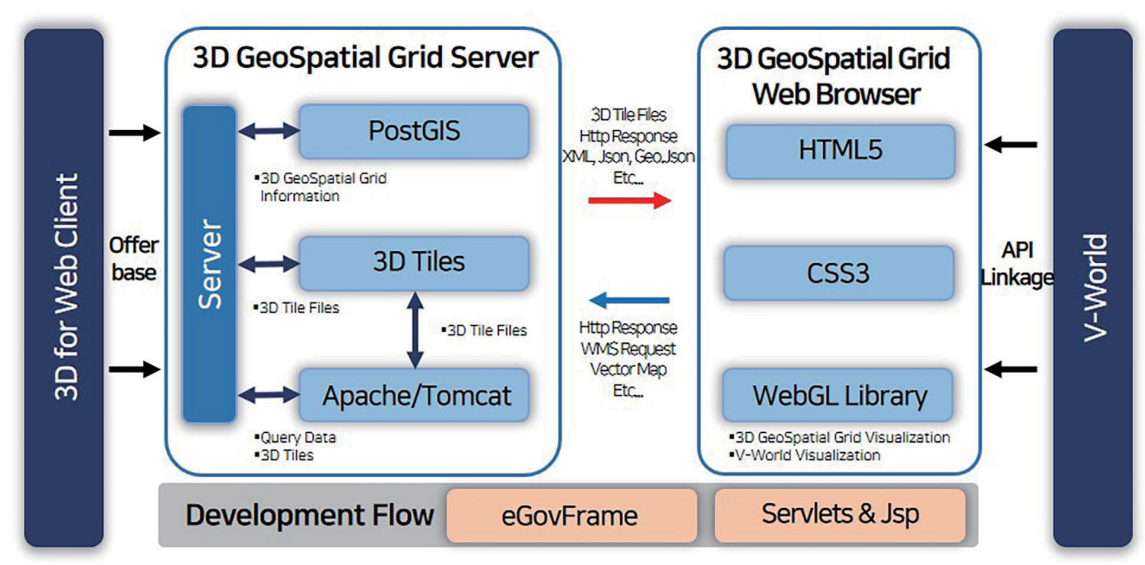

Fig. 4. (Color online) $\mathrm{S} / \mathrm{W}$ analysis environment. 
Table 4

Computer hardware used in analysis environment.

\begin{tabular}{lc}
\hline Category & Specifications \\
\hline $\mathrm{O} / \mathrm{S}$ & Window 10 pro \\
\hline $\mathrm{CPU}$ & AMD Ryzen7 3700x \\
& 8-core 16-thread, 3.60 GHz \\
\hline Memory & $16 \mathrm{~GB}$ \\
& $3000.0 \mathrm{MHz}$ \\
\hline Graphics card & NVIDIA GeForce RTX 2060 Super \\
\hline Web browser & Google Chrome 84.0.4147.135 (64 byte) \\
\hline
\end{tabular}

\subsection{Analysis results}

The results of the visualization of the particulate matter data in the metropolitan area at the regional scope are shown in Figs. 5(a)-5(d). To visualize the particulate matter collected from the metropolitan area effectively and efficiently, this study focused on one day (00:00-23:00, November 29, 2019), which had a particularly high concentration of particulate matter, for 3D visualization. The grid size was set to Level 9 in accordance with the regional spatial scope to input the data in the structured raster data (*.cbr) format inside the grid for visualization. The particulate matter data were filtered to indicate only the average concentration $\left(31 \mu \mathrm{g} / \mathrm{m}^{3}\right)$ or higher according to the atmospheric environment standards designated by the Ministry of Environment, and a polygon mesh with a random color was used for visualization.

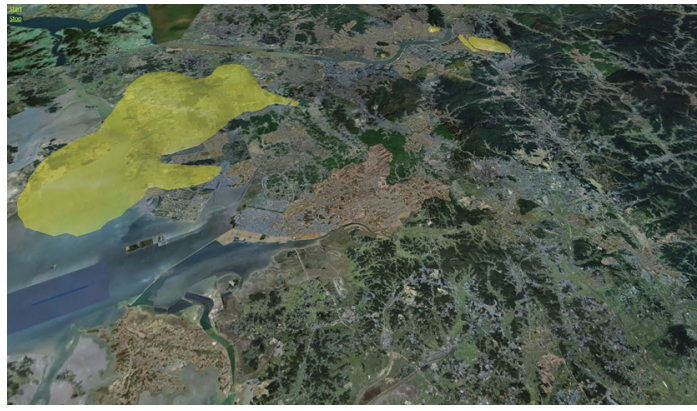

(a)

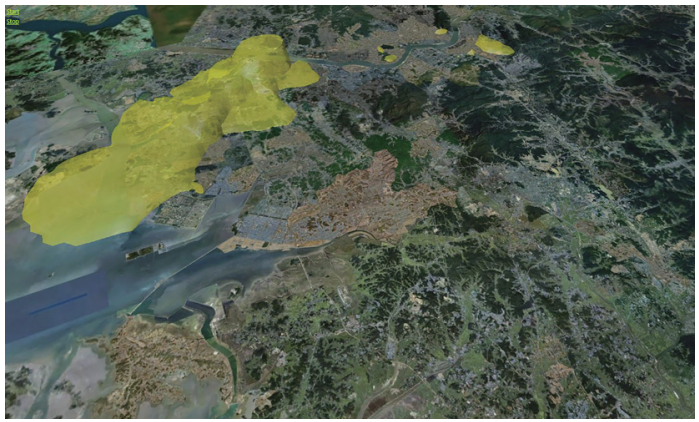

(c)

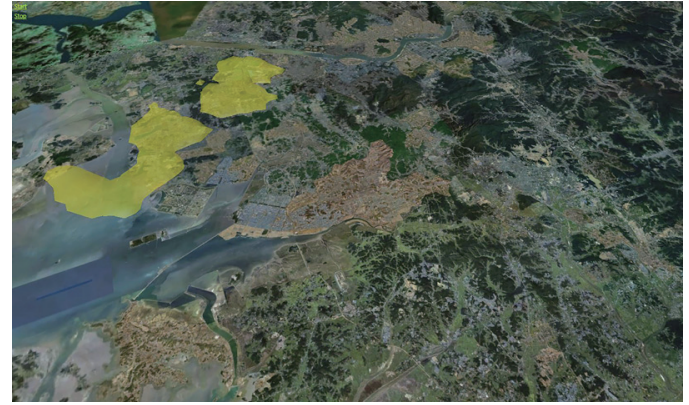

(b)

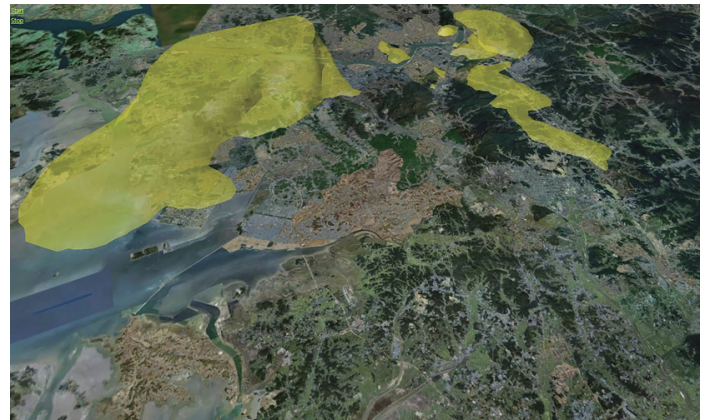

(d)

Fig. 5. (Color online) Visualization results in the metropolitan area over time: (a) 00:00 h, (b) 06:00 h, (c) 12:00 h, and (d) 18:00 h. 
The results of the visualization of the particulate matter data in the metropolitan area in three dimensions demonstrated that Songpa-gu, Gangdong-gu, and Gangseo-gu in Seoul, as well as Seo-gu, Gyeyang-gu, and Bupyeong-gu, which are near the coastal waters of Incheon, had a higher concentration of particulate matter than the other regions. The reason could be inferred to be that Seoul has a high floating population, Songpa-gu has a high traffic volume, and Incheon and Gangseo-gu contain many industrial complexes and large-scale land development projects in progress. In particular, the coastal water of Incheon has a higher concentration of particulate matter than the inland area because particulate matter is blown in by the westerlies.

The visualization results of the particulate matter data in the Gangnam Station area at the local scope are shown in Figs. 6 and 7. The results obtained when the visualization was processed using the particle method by considering the nature of the particulate matter that floated in air are shown in Figs. 6(a)-6(d). Similarly, the concentration of particulate matter over time was represented in random colors according to the atmospheric environment standards designated by the Ministry of Environment. The concentration of particulate matter according to the height could be intuitively identified on the basis of the linkage with V-World. Figures 7(a)-7(d) show the particulate matter concentration in the entire area near Gangnam Station in a grid form. The data have been filtered on the basis of the concentration value. The visualization results of the particulate matter data in the Gangnam Station area in three dimensions demonstrated that the concentration of particulate matter was higher in the commercially dense area (near COEX). In

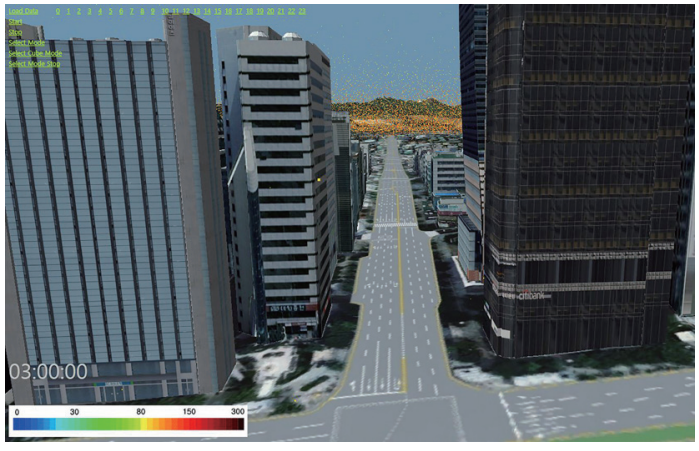

(a)

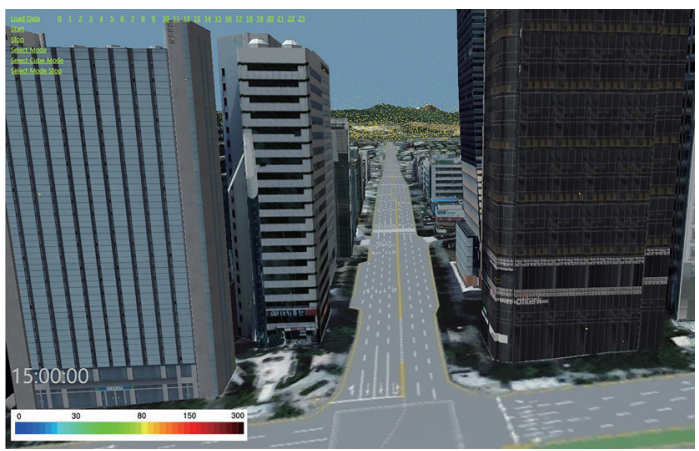

(c)

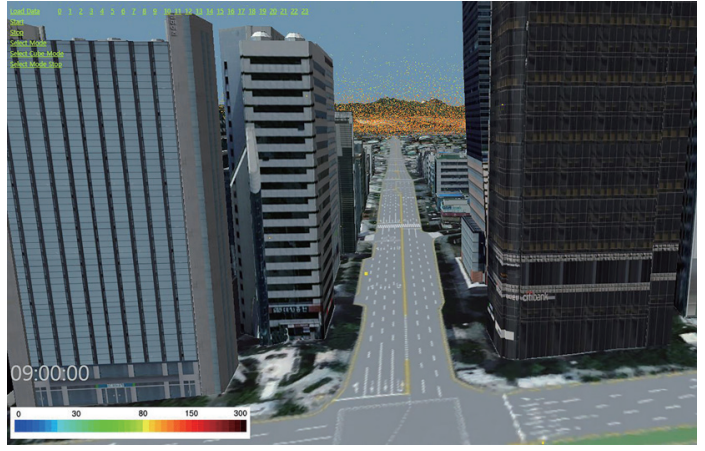

(b)

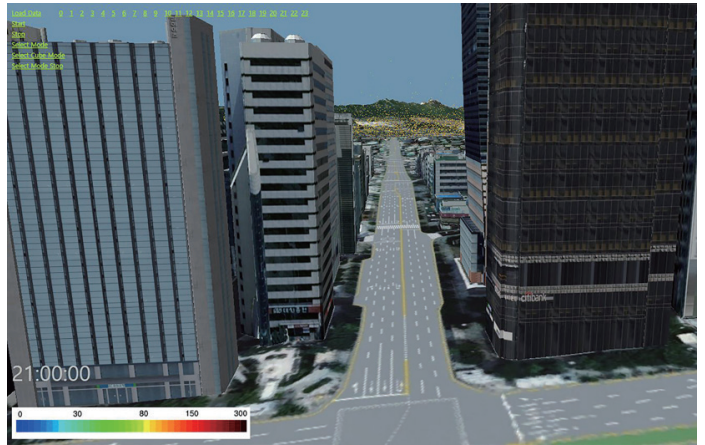

(d)

Fig. 6. (Color online) Visualization results of Gangnam Station area over time using particle method: (a) 03:00 h, (b) 09:00 h, (c) 15:00 h, and (d) 21:00 h. 


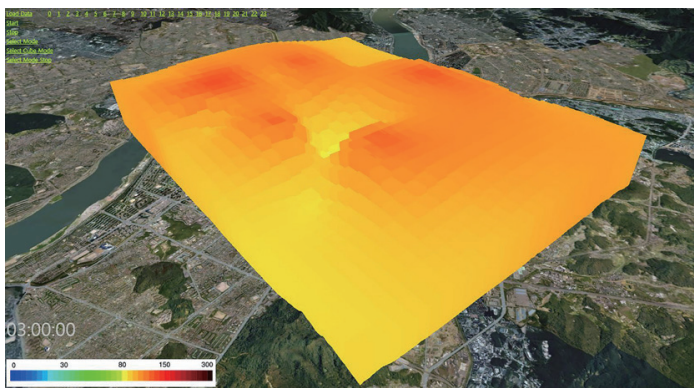

(a)

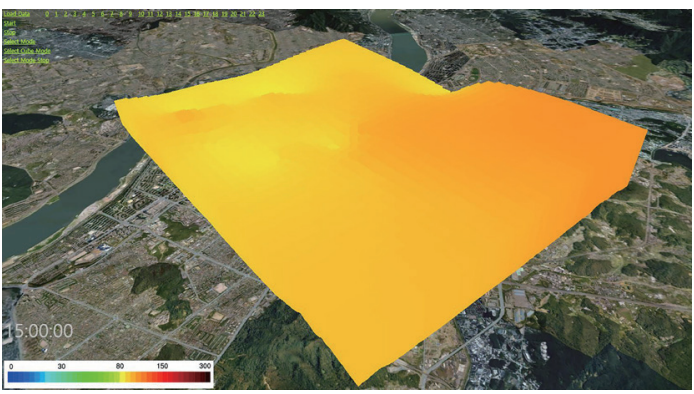

(c)

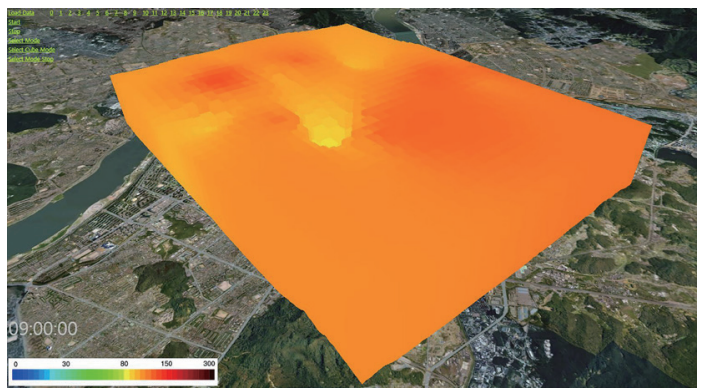

(b)

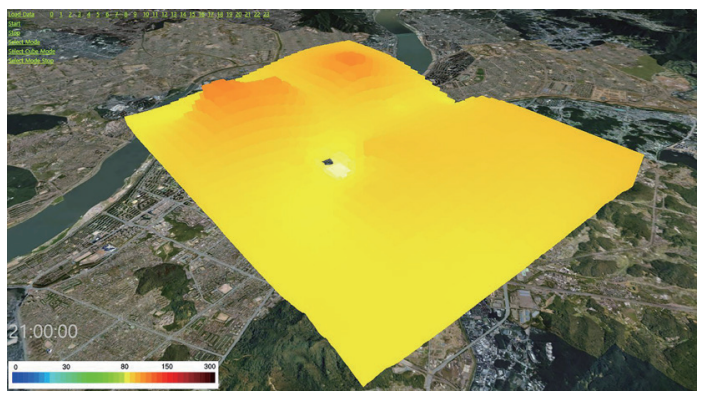

(d)

Fig. 7. (Color online) Visualization results of Gangnam Station area over time in grid form: (a) 03:00 h, (b) 09:00 $\mathrm{h}$, (c) 15:00 h, and (d) 21:00 h.

terms of time, the concentration of particulate matter was higher in the early morning (00:0002:00) and morning (07:00-10:00) than in the afternoon (12:00-15:00) and night (19:00-22:00). Air circulates faster during the day as convection becomes active in the city because of the low pressure caused by solar heat, whereas air becomes stable at night because of the high pressure caused by the low temperature, hence the higher concentration of particulate matter. Moreover, the particulate matter concentration is particularly high during rush hour when high floating population and traffic volume are present.

\subsection{Implications}

The aim of this study was to perform 3D visualization based on 3D geospatial grid technology in which the space was partitioned into a constant grid size according to the spatial scale at the regional and local scopes. Accordingly, 3D visualization was performed by building the data of unobserved points using the GIS spatial interpolation and actual measurement data of particulate matter. The results demonstrated that the concentration of particulate matter varied with the height, and the 3D visualization for the time-series data enabled intuitive information delivery to users. In addition, the visualization of particulate matter data through V-World effectively represented the changes in the spatial distribution of particulate matter in a digital space that resembled the real world. As a result, by delivering information more intuitively than the existing service on particulate matter, individual decision-making processes can be facilitated. Furthermore, the results of the 3D visualization in this study can be utilized as basic materials for establishing a national policy on reducing particulate matter levels. 


\section{Conclusion}

Recently, the demand for 3D spatial information technology has increased so that cities can be effectively managed and that information of interest can be conveniently provided to people. Moreover, the visualization of various types of information has become simpler as technology has advanced. Previously, particulate matter data, which were simply provided as numerical values on a horizontal plane without considering the height, can now be provided with more accurate and practical information.

Many studies on the 3D visualization of particulate matter data have been conducted. However, a majority of these studies were focused on regional areas. Thus, visually examining small-scale areas was difficult. In addition, limitations occurred in representing particulate matter data according to the position and height by dividing the aerial space. More effective visualization methods for overcoming these limitations that are based on research on spatial grid systems are being proposed around the world; however, research on this topic has been insufficient thus far. In the present study, therefore, the concept of the 3D geospatial grid was introduced, and a 3D Geospatial Grid Library was built for 3D visualization. A 3D geospatial grid is a type of spatial information technique in which the aerial space can be continuously and uniformly partitioned, thus enabling the 3D visualization of time-series data on particulate matter that floats in air. Furthermore, effective visualization methods were analyzed by differently defining the grid size for the regional and local scopes. We were able to examine the spatial distribution of highly concentrated particulate matter in the metropolitan area, and the commercially dense area around Gangnam Station showed a particularly high concentration of particulate matter. In addition, highly concentrated particulate matter was present in the early morning as well as during the day.

In terms of data utilization, this study is significant in that $3 \mathrm{D}$ visualization was performed using the NetCDF file format, which is commonly used in the atmospheric science field and for particulate matter data being built by public and private institutions. We actively utilized data that have already been published instead of creating a separate dataset, and we also constructed 3D data for unobserved points by GIS spatial interpolation. However, the 3D data created by GIS spatial interpolation contained estimated values, thereby presenting certain limitations in terms of data accuracy. The particulate matter data collected from the Gangnam Station area were assumed to be measured at the same height without considering the geographical features and gauge height, which was also a limitation in this study. Therefore, different methodologies related to the atmospheric environment can be reviewed to overcome these limitations. Finally, studies on the spatial distribution of particulate matter that varies according to the geographical features and land use and on the difference in the concentration of particulate matter with the height should be conducted in the future to improve data accuracy

\section{References}

1 J. E. Kim and C. H. Hong: JKAIS 18 (2017) 3. http://doi.org/10.5762/KAIS.2017.18.3.56

2 Juřík. V, Herman. L, Snopková. D, Galang. A. J, Stachoň. Z, Chmelík. J, Kubíček. P, and Šašinka. C: PLoS ONE 15 (2020) 5. https://doi.org/10.1371/journal.pone.0233353 
3 J. S. Mehrdad: J. Geogr. Inf. Syst. 9 (2017) 5. https://doi.org/10.4236/jgis.2017.95033

4 World Health Organization: Air Pollution and Child health: Prescribing Clean Air, Summary (World Health Organization, Geneva, 2018) 3.0ed., Chap. 3.

5 A. Kamal, C. Wu, and Z. Lin: Big Earth Data 4 (2020) 2. https://doi.org/10.1080/20964471.2019.1685825

6 P. Y. Chen: EURASIP J. Image Video Process 42 (2019). https://doi.org/10.1186/s13640-019-0443-6

7 G. S. Choi, S. W. Kwon, D. H. Kim, D. Y. Moon, S. W. Jung, S. Y. Lee, and H. Y. Ko: 2016 Proc. 33rd ISARC (IAARC, 2016) 711-719. https://doi.org/10.22260/ISARC2016/0086

8 J. H. Youn, H. W. Kim, S. M. Kim, and T. H. Kim: KSIS 24 (2016) 1. http://doi.org/10.7319/kogsis.2016.24.1.099

9 W. Zhang, L. Han, J. Sun, H. Guo, and J. Dai: 2019 IEEE Int. Conf. Big Data (IEEE, 2019) 1705-1710. http:// doi.org/10.1109/BigData47090.2019.9005568

10 S. Wang, W. Li, and F. Wang: Informatics 4 (2017) 3. http://doi.org/10.3390/informatics4030017

11 S. I. Lee and J. K. Lee: JKHA 26 (2015) 4. https://doi.org/10.6107/JKHA.2015.26.4.055

12 G. W. Kim, H. N. Na, and W. S. Jung: KENSS 28 (2019) 1047. https://doi.org/10.5322/JESI.2019.28.11.1047

13 W. Okuda and T. Kusaka: ISPRS J. Photogramm Remote Sens. 39 (2012) B4. https://doi.org/10.5194/ isprsarchives-XXXIX-B4-331-2012

14 U. Isikdag and K. Sahin: ISPRS J. Photogramm Remote Sens. 42 (2018) 4. https://doi.org/10.5194/isprsarchives-XLII-4-267-2018

15 J. S. Yoo, K. J. Min, and J. W. Ahn: W2GIS 2019: Int. Symp. Web and Wireless Geographical Information Systems (Springer, 2019) 136-149. https://doi.org/10.1007/978-3-030-17246-6 11

16 J. S. Ryu, S. H. Oh, K. J. Min, and J. W. Ahn: KSIS 27 (2019) 6. https://doi.org/10.7319/kogsis.2019.27.6.035

17 S. H. Oh, K. J. Min, K. J. Yoo, and J. W. Ahn: Proc. Korean Society for Geospatial Information Science (KSIS, 2019) 298-299. http://www.dbpia.co.kr/journal/articleDetail?nodeId=NODE08741653

18 H. J. Kim and W. K. Jo: KSIS 20 (2012) 2. https://doi.org/10.7319/kogsis.2012.20.2.003

19 J. M. Ahn and I. H. Park: KSIS 20 (2012) 1. http://www.dbpia.co.kr/journal/articleDetail?nodeId=NODE01821284

\section{About the Authors}

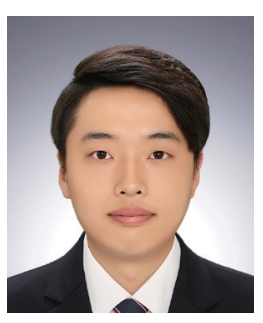

Se Hun Oh received his B.S. and M.S. degrees from Anyang University, Korea, in 2019 and 2021, respectively. He is currently working with AllForLand Co., Ltd. His research interests are in urban planning, big data, smart cities, and spatial information. (sehun0526@all4land.com)

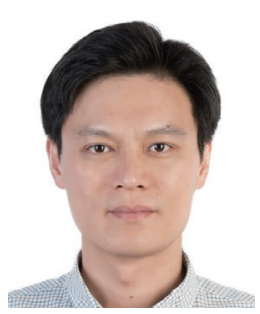

Seon Cheol Yu received his B.S., M.S., and Ph.D. degrees from Anyang University, Korea, in 2003, 2005, and 2011, respectively. From 2011 to 2014, he was an associate research fellow at Korea Research Institute for Human Settlements, Korea. Since 2014, he has been a professor at Anyang University. His research interests are in urban planning, big data, smart cities, and urban regenerations. (scyu@anyang.ac.kr)

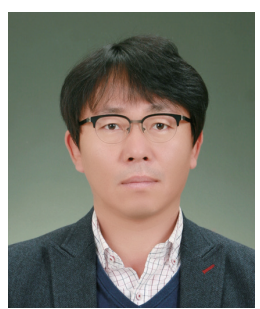

Jong Wook Ahn received his B.S., M.S., and Ph.D. degrees from Anyang University, Korea, in 2000, 2002, and 2007, respectively. From 2007 to 2011, he was an associate research fellow at Korea Research Institute for Human Settlements, Korea. Since 2011, he has been a professor at Anyang University. His research interests are in urban planning, smart cities, big data, and spatial information. (ajw0603@anyang.ac.kr) 